\title{
EL ROL DEL QHAPAQ ÑAN Y LOS APUS EN LA EXPANSIÓN DEL TAWANTINSUYU
}

\author{
THE ROLE OF THE QHAPAQ NAN AND APUS IN THE EXPANSION OF \\ THE TAWANTINSUYU
}

\author{
CHRISTIAN VITRYA
}

En este artículo se plantea la importancia del vínculo entre la red de caminos incas, con su infraestructura edilicia, y los apus o montañas sacralizadas, con su infraestructura simbólica, como elementos fundantes de una nueva y especialmente unificada manera de construir y percibir el paisaje. Se revisan los elementos constituyentes y definitorios de los caminos incaicos y se plantea como hipótesis de trabajo una conquista territorial basada en cinco puntos, que van desde la exploración socioambiental hasta la ocupación efectiva del territorio. Finalmente, se analiza de manera integral la información relacionada con los caminos incas y el paisaje, proponiéndose una clasificación tripartita.

Palabras clave: apus, Qhapaq Nan, arqueología del paisaje, caminos incas, expansión, Período Inca.

In this article, there is a discussion on the significance of the link between the Inca road network, with its physical infrastructure, and the apus or sacralized mountains, with their symbolic infrastructure, as the founding elements of a new and particularly unified way of building and perceiving landscape. There is an analysis of the constituting and defining elements of the Inca roads and a hypothesis consisting of five points, ranging from social and environmental exploration to effective territorial occupation. The article concludes with an integral analysis of the information regarding Inca roads and landscape, which leads to the proposal of a tripartite classification.

Keywords: Apus, Qhapaq Nan, landscape archeology, Inca Roads, expansion, Inca Period.

\section{CONSTRUCCIÓN SOCIAL DE LOS PAISAJES Y LA ADORACIÓN A LAS MONTAÑAS}

Las sociedades del mundo andino prehispánico estuvieron íntimamente ligadas al espacio geográfico, no solo por la producción y obtención de recursos, sino fundamentalmente por la construcción simbólica de los paisajes, hecho que sirvió como herramienta y estrategia en la expansión territorial y dominio político realizado por los incas durante el siglo $\mathrm{xv}$ y primer tercio del siglo XVI.

Se podría decir que la expansión territorial de los Incas operaba en dos escalas o niveles diferentes. Por una parte, vinculando poblados y centros de producción a través de la vasta red de caminos, es decir, el ámbito de lo cotidiano y material; por otro lado, una escala mayor, proyectada desde el horizonte a la esfera celestial, en la que entraron en juego las montañas y el enorme esfuerzo realizado por los Incas para institucionalizar y legitimar-bajo nuevas formas- las antiguas creencias relacionadas con el poder simbólico de los apus.

La construcción social de los espacios fue analizada por diferentes autores de las más variadas disciplinas, quienes en definitiva realizan propuestas vinculadas a

A Christian Vitry, Universidad Nacional de Salta, Facultad de Humanidades. Consejo de Investigación de la Universidad Nacional de Salta. Proyecto No 2108/0. Director del Programa Qhapaq Nan Salta, Subsecretaría de Patrimonio Cultural. Vicente López Nº 195, Salta Capital (4400), Argentina, email: chvitry@yahoo.com 
la jerarquización del espacio como reflejos de las sociedades que lo crean. Eliade (1994), como historiador de las religiones, habla de la contraposición y complementación entre el espacio sagrado y el profano, en que la manifestación de lo sagrado (hierofanía) se les presenta a los hombres en un determinado lugar y tiempo, produciendo una transmutación de ese espacio común en uno especial, cargado de una nueva significación. Augé (1995), desde la antropología contemporánea, habla de los lugares y los no lugares: los primeros están cargados de historia, representatividad social y símbolos. Esta construcción social del espacio es denominada por Augé como lugar antropológico y posee tres rasgos comunes que se consideran identificatorios, relacionales e históricos. Greimas (1980), por su parte, analiza el espacio desde la semiótica, y lo considera una dualidad de significante espacial y significado cultural, en que el primero se refiere a las materialidades tangibles naturales o artificiales y el segundo al significado que cada cultura le atribuye a dichos elementos. Desde la filosofía, a fines de la década de 1960, Foucault (2008) introduce el término heterotopía en contraposición al de utopia, para analizar esos contraespacios que, a diferencia de las utopías, son tangibles y reales, pero a los cuales la sociedad les otorga una significación que restringe su uso cotidiano; así, proyectan un significado que va más allá de la dimensión física y funcional, ya sea de una geoforma o de un edificio o complejo arquitectónico. Llevado a nuestro análisis, podría ser el caso de los centenares de montañas sacralizadas por los incas (figs. 1 y 2), junto con una mayor cantidad de wakas dispersas por el Tawantinsuyu, las que le otorgan una jerarquización de significaciones a los espacios que tienen la finalidad de organizar y ordenarlo (Greimas 1980).

Vemos que estos signos poseen un valor descriptivo, pues nombran los lugares, la vida, la técnica, los seres y los fenómenos naturales, adquiriendo con el tiempo un contenido de carácter emotivo (Duncan 1990). Esta emotividad, cargada de historia y de contenido político o religioso, es la que lleva a las sociedades a crear y habitar espacios que suelen estar acompañados conceptualmente de dobles o modelos con encantos y virtudes superiores al entorno familiar. Surgen entonces los mundos perfectos, libres de males y manchas de lo real, los paraísos perdidos, la utopía, la tierra sin mal, la edad de oro y otras idealizaciones (Eliade 1965; Claval 1999).

Cuando los incas ocuparon el espacio sagrado de los kollas, adoptaron su historia como propia y las mo- dificaciones del espacio expresaron las concepciones de ambos (Niles 1992). Asimismo, hicieron del Cusco algo más que una ciudad central por ser la capital o sede del poder político: fue el centro del cosmos incaico, la zona sagrada por excelencia, la residencia de las wakas de todo el Tawantinsuyu; por ello, se preocuparon de reproducir en el vasto territorio y a menor escala "nuevos cuscos" (Farrington 1998) o centros administrativos y religiosos de variado tamaño, repitiendo en ellos los elementos básicos de la arquitectura y la disposición espacial. Gran cantidad de signos, íconos y símbolos fueron plasmados en el paisaje con la finalidad de transmitir un mensaje visual tangible, conformando una unidad geopolítica del poder plasmada en una serie de formas de ocupación del espacio, diseños arquitectónicos (kallancas, ushnus, hornacinas, adoratorios de altura, etc.), morfología estandarizadas de vasijas, textiles, ofrendas, ceremonias y caminos, entre otros elementos que trascienden al lenguaje escrito y se vinculan con la oralidad. Con ello, generaron puntos de referencia específicos, hitos construidos o significados en el terreno y en el cuerpo social, los que introdujeron un orden y facilitaron la comunicación entre los hombres y el mundo sobrenatural (Bauer 2000).

De esta y muchas otras maneras se fue gestando un nuevo territorio, sumando acontecimientos sociales puntuales de luchas de poder a un proceso territorial genealógico que no se detuvo y que quedó en mayor o menor medida plasmado en el paisaje y también en la memoria colectiva. Los nuevos espacios socialmente construidos fueron portadores de una nueva historia que pretendía arraigarse en el tiempo y ser tradición, como dice Assmann (2008: 15): "El ser que puede ser recordado es texto"; y por ello se refiere a estos lugares como "espacios del recuerdo" cuya finalidad es trascender el tiempo de la memoria social que está acotado casi generacionalmente. En cambio, busca dar lugar a la memoria cultural, la cual es considerada por el autor como la base de la existencia, pues: "No hay comprensión sin memoria, no hay existencia sin tradición" (Assmann 2008: 47). Llevando esta línea de pensamiento al ámbito andino, coincidimos con Sanhueza (2012: 13) cuando expresa que: "Los caminos en sí mismos expresan una forma de concebir y organizar el territorio, de dialogar y de imponerse al entorno geográfico, de jerarquizar y sacralizar ciertos lugares estableciendo la impronta del Estado, dando cuenta de lo que podríamos llamar una cartografía oral del Tahuantinsuyu". Es justamente esta 


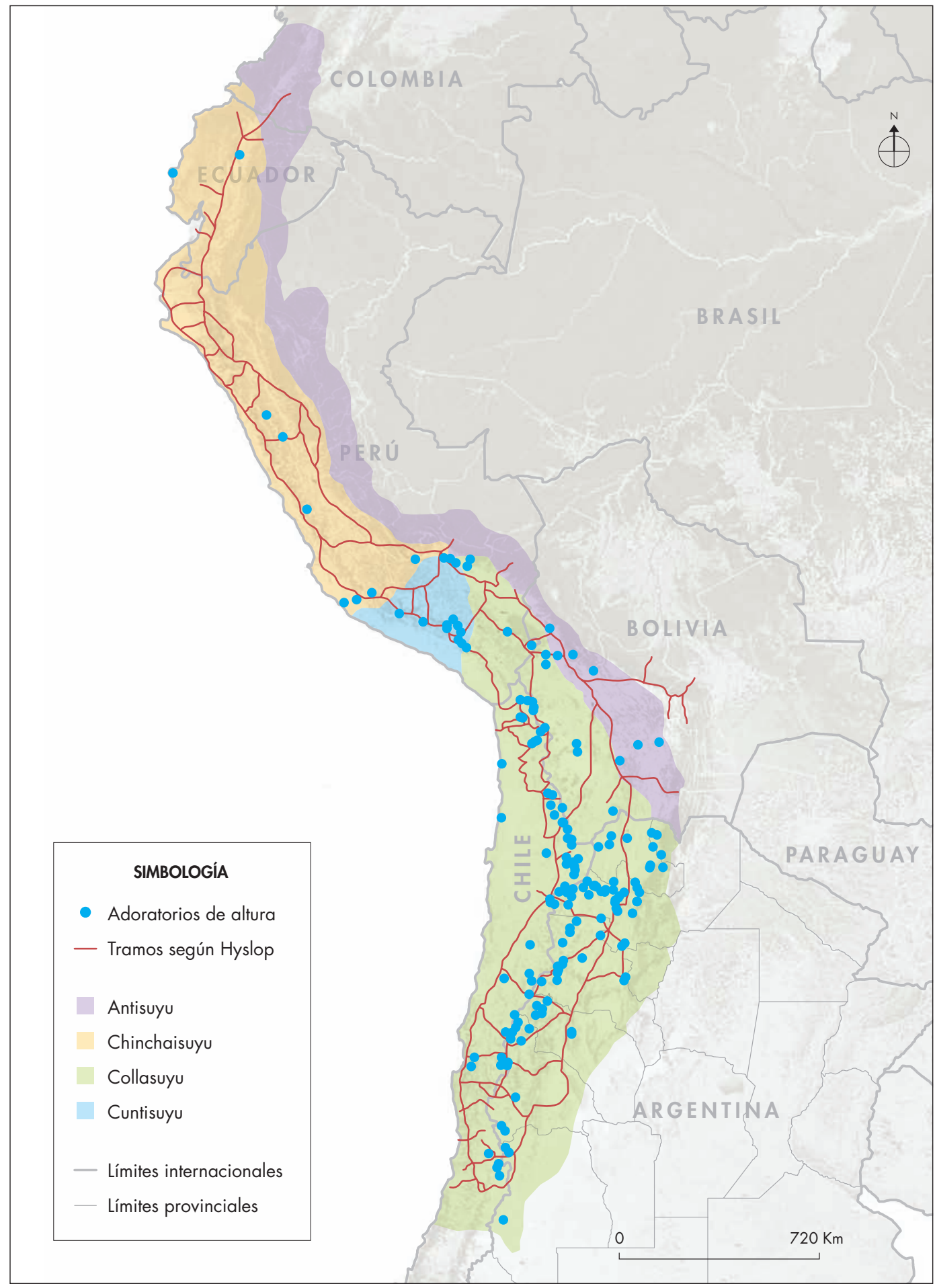

Figura 1. Principales redes viales y adoratorios de altura del Tawantinsuyu. En los Andes se registraron unas doscientas montañas con evidencias arqueológicas, las cuales son divisadas desde el Qhapaq Ñan en forma continua. Figure 1. Main road network and high-altitude shrines in Tawantinsuyu. Nearly two hundred mountains with archeological evidence have been registered in the Andes, which are continuously seen from the Qhapaq Nan. 


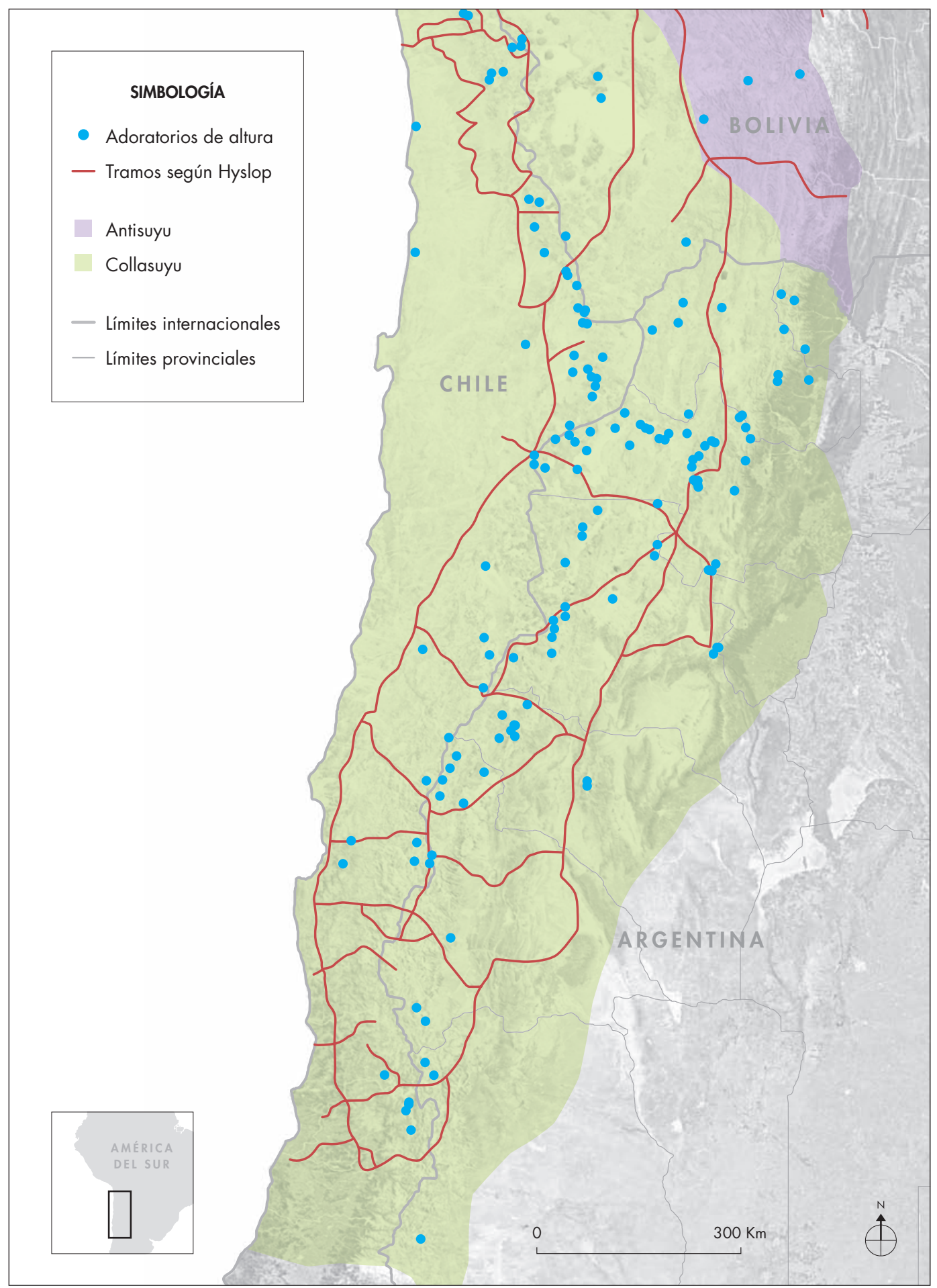

Figura 2. Extremo meridional del Tawantinsuyu donde se localiza más del 50\% de los adoratorios de altura y donde se pudo comprobar la conexión visual existente entre estos y el Qhapaq Ñan. Figure 2. Southernmost end of the Tawantinsuyu, where more than $50 \%$ of the high-altitude shrines are located, and where visual connection between them and the Qhapaq Nan can be demonstrated. 
cartografía oral la que brinda un marco de significado cultural al significante espacial o paisaje donde se va dibujando el Qhapaq Ñan y su anastomosada red que atraviesa kilómetros de distancia por los lugares más inhóspitos del territorio andino.

Las montañas, que habían sido veneradas desde tiempos inmemoriales pero no ascendidas por ser la morada exclusiva de los apus o deidades, fueron escaladas por los incas y resignificadas con nuevas y valiosas ofrendas, lo que en cierta forma contribuyó al refuerzo del dominio religioso, ya que a la vista de los grupos dominados, los incas entablaron una comunicación más directa con los apus. ¿Cuáles son los motivos para adorar a las montañas? Es una pregunta que muchas veces nos realizamos ante la abrumadora evidencia arqueológica registrada en las montañas durante un siglo (Beorchia Nigris 1987).

Besom (2009: 117-145) realiza un exhaustivo y prolijo análisis de los cronistas que se refirieron al culto de las montañas y los clasifica en quince categorías que merece la pena nombrar: (1) la naturaleza extraordinaria de los cerros; (2) su rol preponderante en la mitología andina; (3) su papel transicional o como "peldaño" hacia los dioses superiores; (4) su capacidad para controlar los fenómenos meteorológicos; (5) su asociación con el agua; (6) su relación con la salud humana; (7) su asociación con la producción económica; (8) su relación con los viajes; (9) su capacidad de asustar o intimidar; (10) sus funciones oraculares; (11) su incorporación y rol en las líneas de visión; (12) su función como marcadores de límites y fronteras; (13) su rol relacionado con la unión de personas de diferentes comunidades; (14) su función simbólica con respecto al bienestar del imperio y (15) su manipulación para crear y reforzar las relaciones de poder.

A esta exhaustiva lista de motivos prácticamente no resta agregarle nada y, aunque el autor citado lo menciona en su análisis, deseamos destacar la importancia que tiene la imponencia visual de la montaña en esa ruptura de la horizontalidad y su proyección vertical hacia el cielo; asimismo, su belleza, su íntima relación con la minería (Cruz 2009; Salazar et al. 2013) y su humanización, hecho que ha demostrado Bastien (1978) en la denominada Montaña del Cóndor, en cuyos diferentes pisos ecológicos las comunidades kallawayas de Bolivia basan su organización social y espacial.

Las montañas poseen una doble función, pues, como grandes hitos marcan una presencia y un punto de referencia en la organización espacial; asimismo, como geosímbolos le aportan una historia al paisaje que contribuye a la consolidación de esa cartografía oral andina (Sanhueza 2012) que actúa como pivote de la identidad y de la legitimación de un nuevo orden socioespacial propuesto por los incas en su proceso expansión.

\section{Expansión inca: una propuesta}

La conectividad del mundo andino prehispánico data de varios siglos antes de la expansión Inca. Al respecto, existen abundantes evidencias -especialmente para el área centro sur de los Andes- sobre el tráfico multiambiental de los caravaneros, quienes fueron los responsables de generar un complejo proceso de circulación de bienes domésticos y de estatus entre los distintos y alejados territorios (Nuñez \& Dillehay 1995 [1979]; Nielsen 1997; Berenguer 2004; y otros), los cuales no serán abordadas en el presente artículo.

Es a través de las crónicas que se sabe con bastante detalle la historia de los incas; aunque sesgadas por motivos políticos que la etnohistoria analiza pormenorizadamente desde hace décadas, ellas nos aportan suficiente información respecto a la forma en que el espacio fue colonizado (Murra 2002). En tal sentido, el relato mítico de Felipe Guamán Poma de Ayala (1992 [1614]; Sanhueza 2012) nos habla acerca de determinadas prácticas "civilizatorias" tendientes al orden social, político, religioso y, de hecho, espacial, ya que a través del amojonamiento y deslinde de tierras el Inca sentaba las bases para la legitimación del nuevo orden político. El cronista Betanzos (1987 [1551]) nos dice que los incas, al tomar posesión de una nueva "provincia", diseñaba o "pintaba", "medía", "amojonaba" y "repartía" sus territorios y recursos, generando un ordenamiento territorial del espacio social y productivo, a lo que necesariamente se sumaba el espacio religioso o mítico. Todo este proceso "civilizatorio" y de conquista tuvo como eje principal el desarrollo del sistema vial, que de acuerdo a las descripciones de los cronistas estaba organizado y señalizado según determinadas técnicas de medición de distancias (Cieza de León 2005 [1553]; González Holguín 1989 [1608]; Bertonio 1984 [1612]; Guamán Poma de Ayala 1992 [1614], Sanhueza 2012), que fue interpretado como "leguas del Inca" (González Holguín 1989 [1608]). Las evidencias arqueológicas se condicen bastante con las crónicas en este punto, pues la gran cantidad de mojones, hitos, sayhuas, apachetas y otros dispositivos repartidos en los espacios circun- 
dantes a los caminos dan cuenta de este sistemático procedimiento de conquista y organización territorial (Vitry 2000; Sanhueza 2004, 2012).

Sobre la base de lo antedicho, y teniendo en cuenta algunas de las variables posibles del proceso de construcción de paisajes y consolidación de un nuevo orden geopolítico, se intentará hipotetizar de forma esquemática sobre procesos que pudieron haber ocurrido durante el avance de los incas en los territorios conquistados, sin olvidar que, al menos arqueológicamente y particularmente en zonas alejadas del Cusco, lo incaico se debe pensar en función de los grupos que fueron incorporados a la propuesta política del Tawantinsuyu.

Se sugiere entonces la siguiente y posible secuencia en el proceso de conquista territorial: (1) exploración socioambiental, (2) estrategias de negociación con los líderes políticos, (3) planificación estratégica, (4) construcción de infraestructura vial y (5) ocupación efectiva del territorio y funcionamiento pleno.

La exploración socioambiental se refiere al hecho de recabar información de los territorios, tanto de manera indirecta como directa, para elaborar un panorama completo de los recursos humanos y ambientales reinantes en cada una de las zonas que pretendían conquistar. Muchas de las poblaciones andinas de los siglos Xv y xvi estaban organizadas en forma segmentaria, siendo la base de estas estructuras los ayllus, es decir, grupos de personas que administraban colectivamente recursos naturales estratégicos y entre ellos se consideraban parientes por descender de un antepasado común, fuera este real o mítico. Estos ayllus menores o pachaqas se agrupaban en organizaciones mayores de ayllus, mitades, grupos étnicos y confederaciones (Nielsen \& Boschi 2007: 46). Seguramente se informaron entre grupos étnicos y al interior de ellos sobre los conflictos, las jerarquizaciones internas, liderazgos, técnicas productivas, especificidades, redes de intercambio, principales productos o bienes intercambiables, etc., es decir, es imaginable un trabajo de inteligencia que les habría permitido tener un diagnóstico e información clave para poder diseñar una estrategia de negociación con cada uno de los líderes políticos. Contando con toda la información territorialsocial y habiendo analizado y seguramente discutido internamente las diferentes estrategias de negociación futura, ya fuera llegando a un acuerdo pacífico o a una confrontación bélica, debieron haberse puesto recién en contacto con los líderes políticos para acordar los encuentros y poder plantear la propuesta y escuchar las contrapropuestas. Los resultados de estas decisiones son los que hoy podemos comprobar arqueológicamente, como hemos observado en Tastil (Salta, Noroeste de Argentina). Allí, los incas cambiaron la polaridad de los centros de consumo, producción e intercambio preexistentes, dotando al lugar de una nueva lógica espacial, dinámica del movimiento de las personas y control de las mismas junto al espacio geográfico. En este proceso, el gran eje ordenador fue el sistema vial y la infraestructura asociada (fig. 3), la cual, además de los edificios tradicionales, tenía también dispositivos de control ubicados en lomadas (Vitry 2005). La desestructuración espacial está directamente relacionada con la simbólica en mayor o menor medida, pudiendo manifestarse a gran escala, como la recientemente mencionada, o a pequeña escala, como el caso del sitio arqueológico Los Amarillos, ubicado en la Quebrada de Humahuaca, donde los incas destruyeron de manera violenta los principales emblemas del poder político y simbólico precedente (Nielsen \& Walker 1999; Nielsen \& Boschi 2007). Existen pocos casos en la región donde se haya registrado tanta violencia en el proceso de expansión e incorporación de poblados al Tawantinsuyu. Si bien está acotada en el espacio, la conquista ritual y dominación política perpetrada en Los Amarillos debió tener un impacto a gran escala geográfica y también temporal, sirviendo como advertencia a los poblados de la región. A este tipo de ejemplo se puede sumar el de sitios como Turi, La Paya, Pucará de Tilcara y otros que tienen particularidades edilicias que dan cuenta de acuerdos violentos o pacíficos (Raffino 2007).

Una vez concluidas las negociaciones, los incas ya se encontraban en el nuevo territorio, lo que les permitía trabajar en una suerte de planificación estratégica sobre la base de los recursos, personas, conectividad y situación de la sociedad luego del acuerdo. En esta fase, se puede advertir que hubo una relación de dominante y dominado -aunque no haya corrido sangre- $y$ una buena cantidad de detalles, no solo del lugar sino también en relación con los vecinos próximos y antiguas formas de intercambiar bienes, que servirían de punto de partida para poder llevar a la práctica el ejercicio del poder en el nuevo escenario. Una de las principales obras debió ser la construcción de los caminos y la infraestructura vial asociada, ya fuera empleando las sendas existentes, realizando modificaciones de trazado previo o bien construyendo una nueva vía, según el caso. Todo esto debió requerir un ejercicio del poder muy fuerte, 

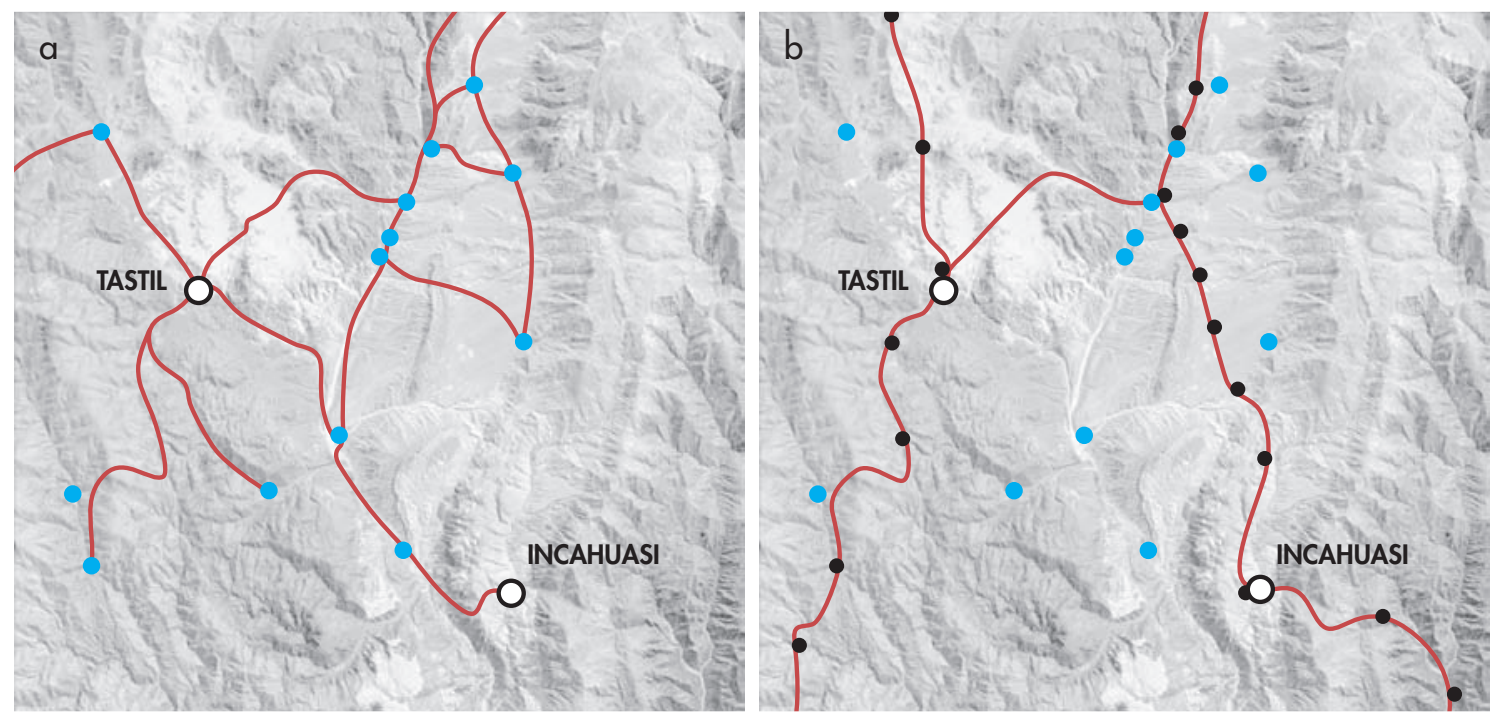

Figura 3. Desestructuración espacial llevada a cabo por los Incas en relación con el poblado de Tastil: a) principales zonas productivas y vías de comunicación que convergen en Tastil; b) reconfiguración del espacio realizada por los incas, dejando de lado el poblado de Tastil y priorizando las zonas productivas. Figure 3. Spatial destructuring by the Inca regarding the town of Tastil: a) main productive areas and communicating roads that converge in Tastil; $\boldsymbol{b}$ ) spatial reconfiguration by the Inca, who left Tastil aside and prioritized productive areas.

ya fuera mediante estrategias de liderazgo acordadas con los curacas locales o a través de la imposición en cualquiera de sus posibles formas. No debió ser fácil en ningún lugar instaurar un nuevo régimen por más convincente que fuera, ya que, de una manera u otra, los pobladores cedieron o perdieron parte de su libertad y forma tradicional de vida a favor de un proyecto ajeno. Finalmente, se produce la ocupación efectiva del territorio y funcionamiento pleno en el nuevo panorama geopolítico. Si bien con anterioridad el territorio ya estaba ocupado por los incas, se considera como el fin del ciclo y el inicio de otro a la culminación de las obras que permitirían a dirigentes y ejércitos moverse a través del sistema vial. Esto no quiere decir que las obras necesariamente hayan tenido que estar terminadas, pues la literatura arqueológica nos brinda sobrados ejemplos de obras inconclusas, ampliaciones posteriores, arreglos o modificaciones realizadas, etc. Todo ello nos sugiere la dinámica del proceso que se fue adaptando a las coyunturas que se les presentaban en cada lugar.

Este esquema hipotético no debería ser pensado de manera lineal ni evolutiva, pues, como se dijo anteriormente, desde el punto de vista arqueológico, la experiencia nos indica que lo incaico se define por lo preexistente y el tipo de acuerdo al que llegan y no al revés. La infraestructura edilicia inca tiene ciertos elementos que debe cumplir, pero la mano de obra local le imprime indefectiblemente su sello. No estamos frente a una tropilla de constructores incas que se diseminaron por el Tawantinsuyu, sino frente a constructores locales que seguían las pautas de construcción que se les indicaba. No hay que perder de vista tampoco los procesos en sí mismos, pues también sabemos por la etnohistoria de levantamientos, traiciones, resistencias, reocupaciones, traslado de comunidades completas y una buena cantidad de situaciones conflictivas que obviamente repercuten de una u otra manera en el registro arqueológico (Murra 2002).

Este modelo esquemático planteado nos hace pensar, salvando las diferencias, en lo que los urbanistas denominan un tipo de expansión tentacular dispersa ${ }^{1} \mathrm{y}$ también expansión capilar, ${ }^{2}$ las cuales se relacionan con el crecimiento urbano en torno a una vialidad principal, en el caso del primer ejemplo, o bien, en el desarrollo y crecimiento que se manifiesta a través de las vías secundarias (Pozo Urquizo 2011: 114). Lo que nos interesa, más allá de las características técnicas o teóricas de los tipos de expansión mencionados, es el concepto de una expansión que se va haciendo efectiva a través de caminos y poblados, líneas y puntos, nodos e internodos, brazos que se van expandiendo y vinculando con un centro lejano; lo importante es que dicha vinculación es real y tangible, un sistema vial que no solo está plasmado en el paisaje sino también integrado al mismo desde 
un punto de vista tanto económico como simbólico y ritual. En un mundo desconocido, lejos del Cusco, los caminos constituían lo conocido y propio; los tambos, chasquiwasis, centros administrativos, apachetas e hitos, junto con los detalles constructivos de los edificios como las hornacinas trapezoidales, brindaban esa sensación de "estar en casa". La construcción de tan vasto sistema vial sin dudas fue mucho más allá de un mero soporte para el traslado de personas o productos; representaba también un anclaje al propio mundo en tierras lejanas, un vínculo con la identidad, tanto hacia adentro como hacia afuera, un emblema detentado por el estado a miles de kilómetros del principal centro y un sello definitivo de la conquista realizada (Sánchez 1992; Eliade 1994).

Esta manera de expandirse e ir ingresando a un territorio "nuevo" implicó también la creación de puntos fijos y claramente visibles del horizonte: me refiero particularmente a las montañas sagradas, es decir, los geosímbolos propuestos por Bonnemaison (1992: 76), quien afirma que: "los geo-símbolos son 'lugares', relieves, itinerarios, rutas, construcciones, sitios, etc. que, por razones religiosas, culturales o políticas, adoptan en los ojos de los grupos étnicos y sociales una dimensión simbólica que los arraiga en su identidad, y que por ende, participa activamente en la construcción territorial" (en Cruz \& Jara 2011: 76).

En los Andes, por lo que conocemos hasta el presente, los incas ascendieron dos centenares de montañas y en ellas erigieron construcciones de carácter ceremonial donde llegaron a ofrendar vidas humanas (Beorchia Nigris 1987; Vitry 1997; Schobinger 1998; Reinhard \& Ceruti 2000; Besom 2009; y otros). Desde el punto de vista visual, podemos decir que este complejo de montañas no tiene interrupciones desde el Cusco hasta el cerro El Plomo en Chile o el Aconcagua en Argentina (figs. 1 y 2). La visibilidad en la cordillera puede abarcar centenares de kilómetros, tal como pudimos comprobar en la cima del Llullaillaco, desde donde se divisa el Nevado de Cachi situado a 220 kilómetros hacia al este; o en el volcán Antofalla, que permite observar el Pular y Pajonales a $180 \mathrm{~km}$ (fig. 4). Asimismo, las montañas sacralizadas siempre son observadas desde el Qhapaq Nan, como si le diesen un marco de contención, protección o pertenencia al sistema vial (fig. 5). Cuando se transita por el Qhapaq Nan siempre hay alguna montaña u otro geosímbolo de referencia. En este sentido, es importante comentar el carácter dual que tienen las vialidades, pues no es lo mismo transitar en un sentido que en el otro: se trata de paisajes diferentes, donde lo que hace la diferencia son determinadas geoformas que se destacan y pueden ser reconocidas tanto a la ida como al regreso.

Los caminos avanzan en horizontal, asociados a una buena cantidad de infraestructura de soporte de carácter administrativo que responde a las necesidades biológicas humanas. Asimismo, en un nivel macro, sobre la línea del horizonte y proyectándose hacia arriba se encuentran las montañas y sus apus, brindando un soporte de carácter simbólico, una geografía sagrada que nos remite a una cartografía oral con profundo sentido cultural (Sanhueza 2012), de manera tal que apus y Qhapaq Ñan se encuentran íntimamente vinculados en el proceso de avance y creación de los nuevos espacios incaizados fuera del Cusco (fig. 6).

\section{Análisis integral del camino y su entorno}

Venimos sugiriendo que los caminos jugaron un rol determinante en el proceso de conquista de los nuevos territorios anexados al Tawantinsuyu. Asimismo, existe una impronta en estos caminos que nos hacen identificarlos, al menos en lugares alejados del Cusco como el Noroeste Argentino y el norte de Chile. Así como Raffino (1981) identificara rasgos de primer y segundo orden para la arquitectura inca, podemos hacer lo mismo para los caminos y la infraestructura asociada. Sin embargo, como el abordaje implica también el paisaje asociado y la importancia de la geografía sagrada en la definición de los caminos, ese tipo de clasificación nos resulta insuficiente y solamente aplicable a una parte relacionada con la infraestructura caminera y sus características puntuales a las que se refirieron numerosos autores (Raffino 1981 y 2007; Pereira 1982; Niemeyer \& Rivera 1983; Santoro 1983; Hyslop 1984, 1992; Muñoz et al. 1987; Stehberg 1995; Vitry 2000; Castro et al. 2004; Fresco 2004; Berenguer et al. 2005; González 2007; Avilés 2008; Manzo et al. 2011; Moralejo 2011; Sánchez Canedo 2012; entre otros).

Se considera que al estudio de caminos incas no debiera faltarle un análisis profundo del paisaje asociado, ya sea de las geoformas destacadas como wakas, las montañas circundantes, como también de todos los espacios relacionados con el agua, tales como las nacientes, lagos, ríos, arroyos y humedales, pues en lugares semidesérticos estos recursos son muy valiosos y por ende están investidos de sacralidad. 


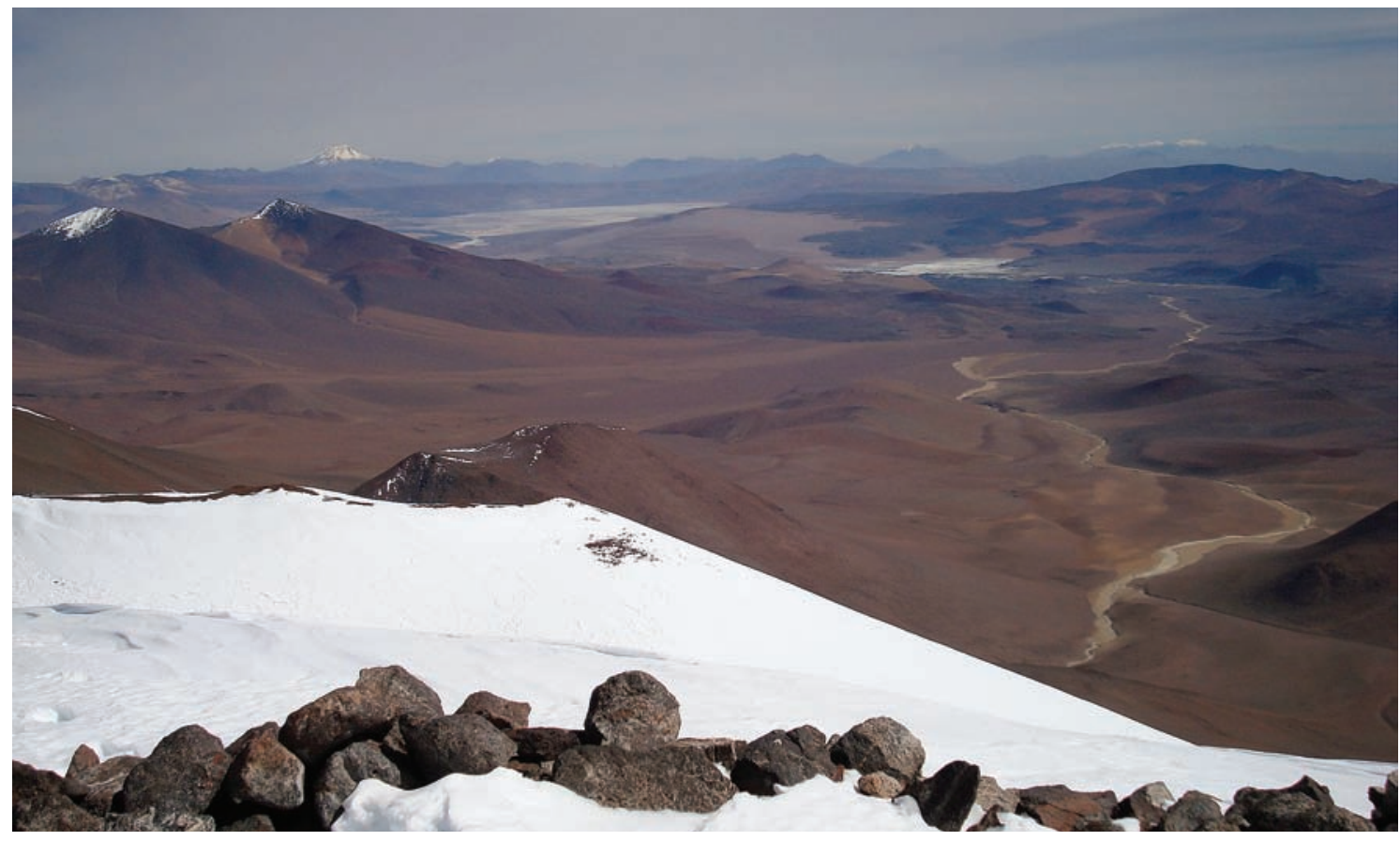

Figura 4. Vista desde el volcán Antofalla $(6.450 \mathrm{~m})$ en la puna de Catamarca, desde donde se divisa el volcán Llullaillaco y los cerros Pular y Pajonales, ambos ubicados a casi $200 \mathrm{~km}$ de distancia. Figure 4. View from the Antofalla volcano (6,450 $\mathrm{m})$ in the Catamarca puna, where the Llullaillaco volcano and the mountains Pular y Pajonales, both located almost $200 \mathrm{~km}$ away, can be seen.

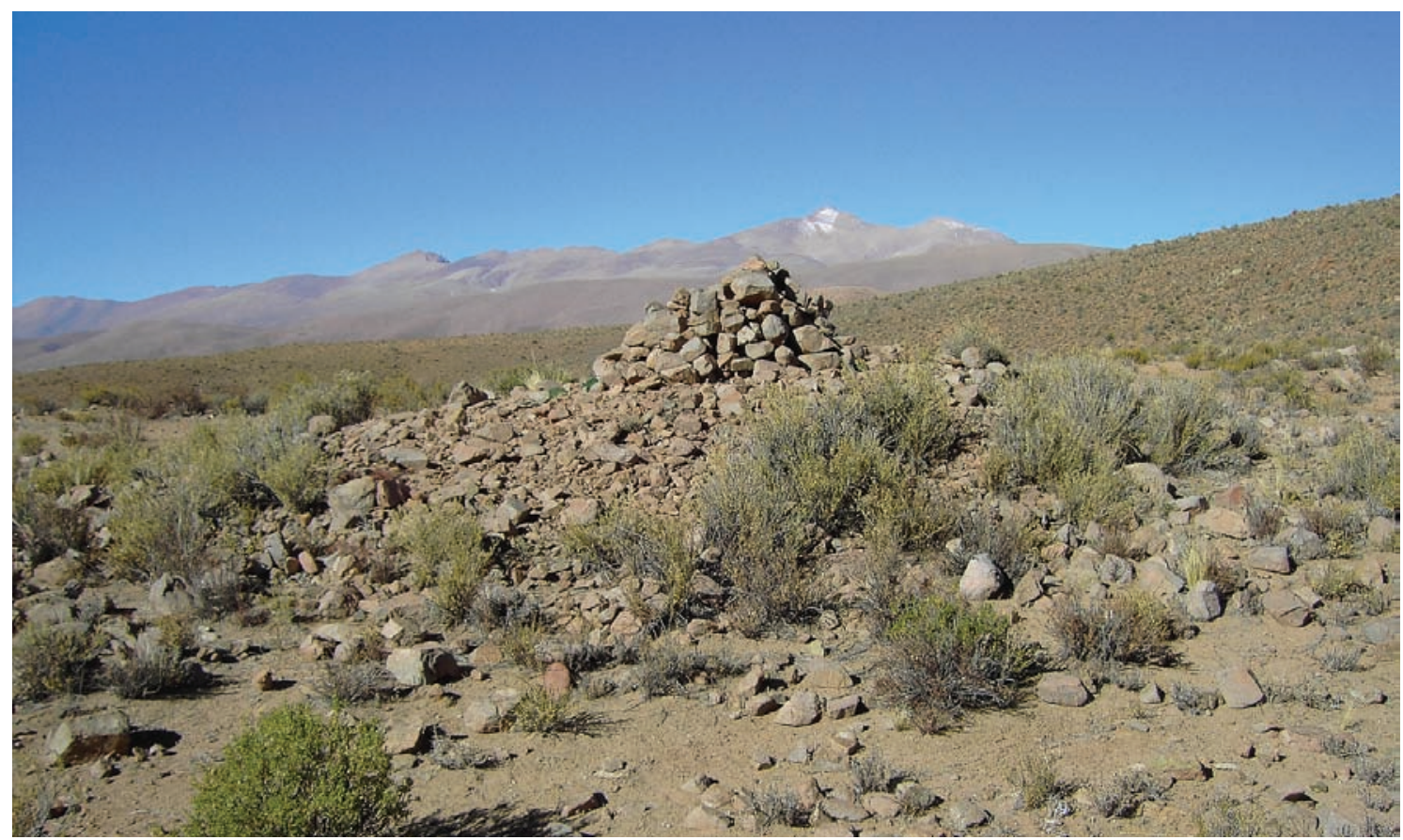

Figura 5. Apacheta de El Palomar junto al Qhapaq Ñan, desde donde se divisa el nevado de Chañi en forma constante y durante varias decenas de kilómetros de recorrido. Apus y Qhapaq Ñan están conectados visualmente. Figure 5. Apacheta of El Palomar next to the Qhapaq Nan, where nevado de Chañi can be seen constantly for several tens of kilometers. The apus and the Qhapaq Nan are visually connected. 


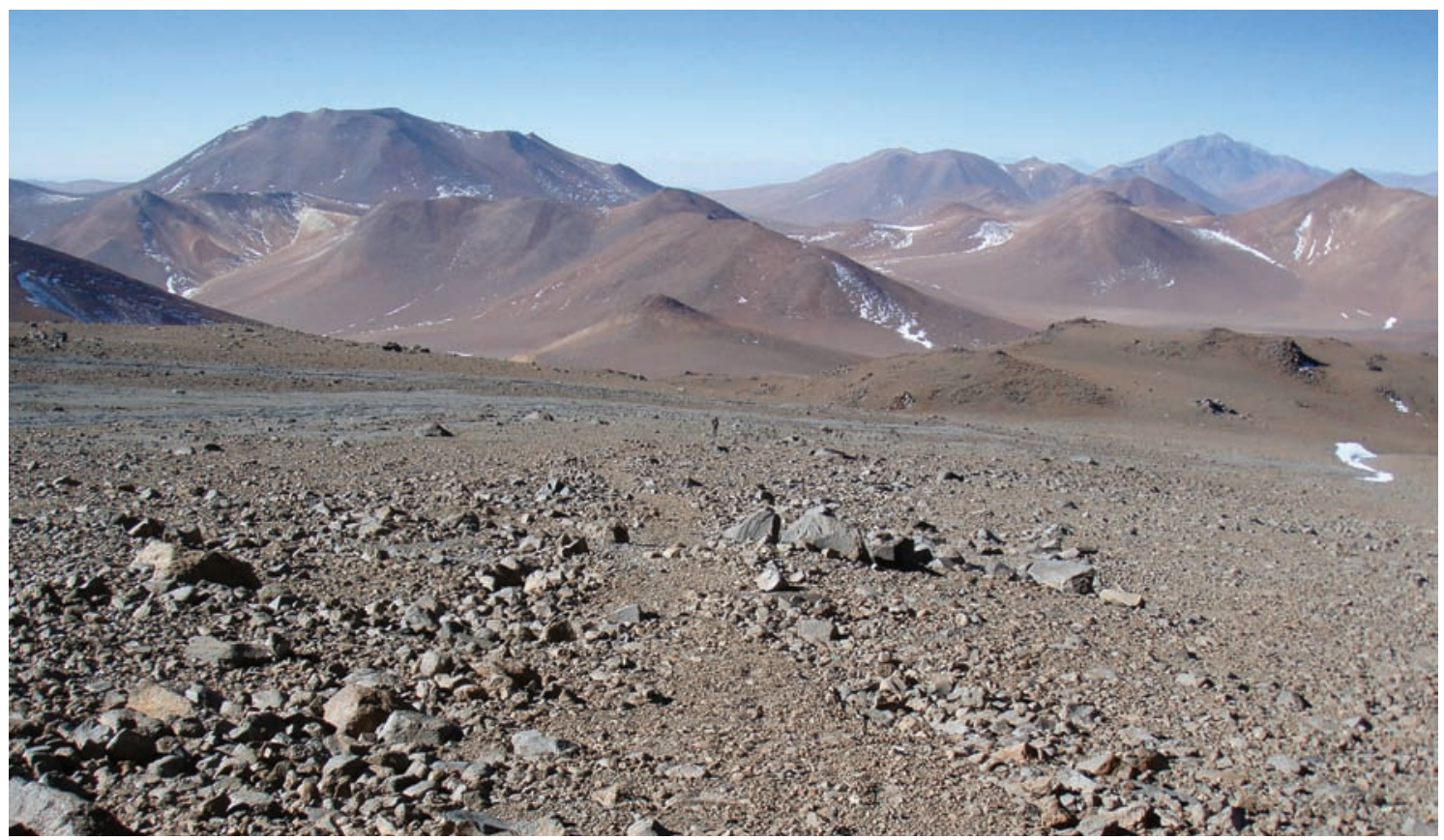

Figura 6. Camino ceremonial que asciende al volcán Llullaillaco. Al fondo se divisan otros apus, como el cerro Inca o Chuculai y el volcán Socompa. En la montaña, los caminos marcan un lugar diferenciado del resto tanto física como simbólicamente. Figure 6. Ceremonial road ascending the Llullaillaco volcano. Other apus can be seen in the background, such as the mount Inca (Chuculai) and the Socompa volcano. Roads mark a differentiated place from the rest of the mountain both physically and symbolically.

Finalmente, nuestro análisis desde la perspectiva del paisaje debe considerar la percepción cultural del espacio, que podemos definir como andina y occidental. Nuestra disciplina (arqueológica en particular y de las ciencias sociales en general) y nuestra forma de vida están signadas por la cultura occidental, lo cual nos lleva muchas veces a planteamientos o conclusiones sesgadas. Por ello, debemos realizar un esfuerzo considerable para poder pensar y analizar los espacios con criterio andino. Para ejemplificar lo dicho, baste utilizar las mismas montañas, que en el mundo andino estaban significadas como lugares de importancia: estructuraban el espacio, vinculaban a las personas y también estaban humanizadas a través de relatos e historias míticas fundantes (Bastien 1978; Beorchia Nigris 1987; Besom 2009). En la concepción occidental, las montañas representan barreras y normalmente dividen, ya que son límites naturales (internacionales, nacionales y regionales), están despersonalizadas y no representan nada desde una perspectiva simbólica o cultural. De esta manera, también la utilización de los espacios es diferente; los andinos prehispanos utilizaban las quebradas y valles estrechos como lugares de intercambio (tinku) donde dejaban crecer los árboles nativos para extraer madera y frutos, mientras que los asentamientos, terrazas de cultivos y caminos los realizaban a media ladera; las cumbres y filos montañosos eran utilizados para comunicarse, a veces con caminos principales (fig. 7). En la concepción occidental del espacio, se tiende a concentrar todas las actividades en los fondos de valles y quebradas, en detrimento del resto de la montaña que representa un obstáculo y un lugar no apto para los modernos medios de transporte (Vitry 2010).

Deberíamos pensar los elementos recientemente mencionados de manera integrada en un sistema mucho mayor y complejo, pero no por ello incoherente, sino todo lo contrario; estamos frente a historia y situaciones microrregionales que se integran a una superestructura política, cultural y simbólica proveniente del Cusco a nivel macrorregional, entretejiendo un nuevo y por cierto último capítulo de la historia prehispánica andina.

Siguiendo los lineamientos metodológicos de Otero Vilariño (2003: 6), que considero adecuados para ayudar a pensar, quizás de una manera más organizada, la complejidad de los caminos incas, me permito readaptarla del mundo ibérico al andino y de 


\section{ESPACIO GEOGRÁFICO}

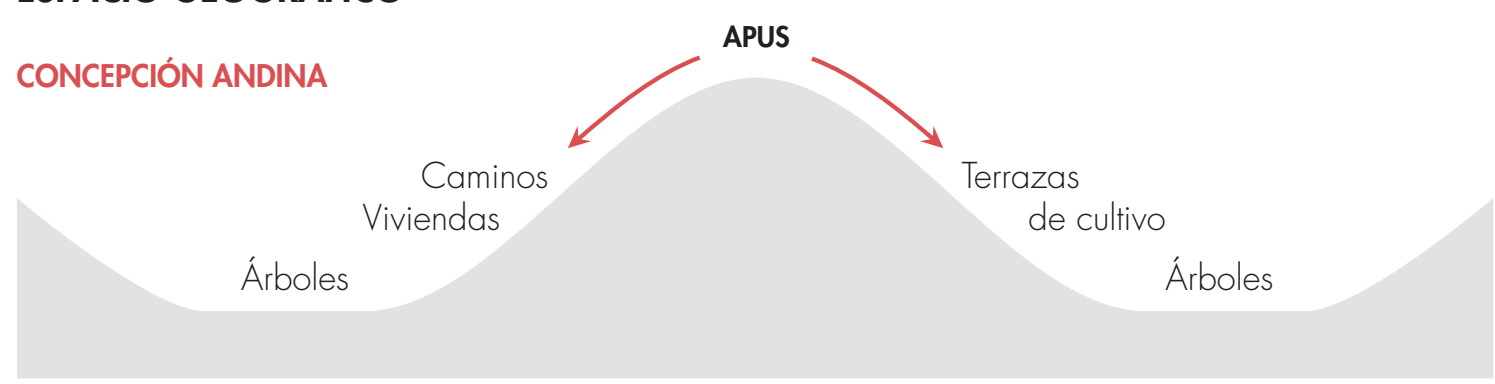

\section{CONCEPCIÓN OCCIDENTAL}

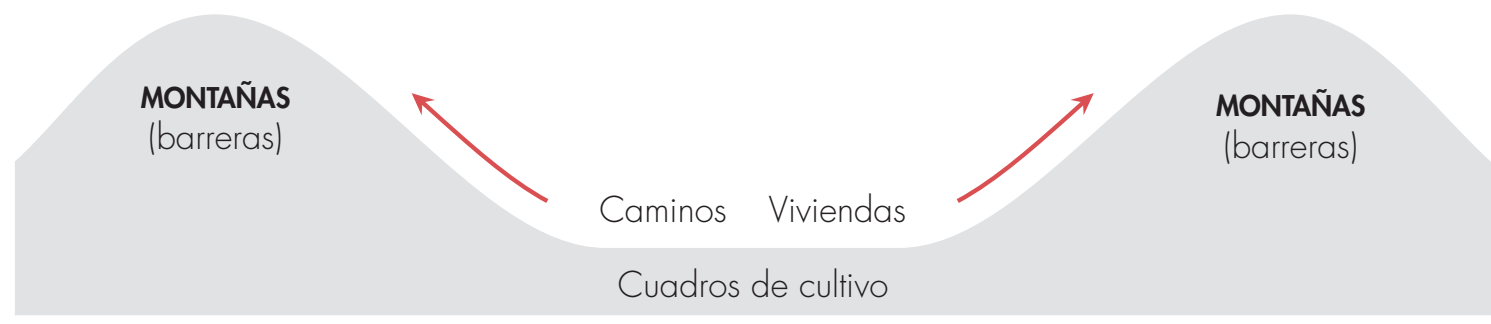

Figura 7. Dos maneras diferentes de concebir un mismo espacio, un claro ejemplo de cómo las sociedades construyen y significan sus paisajes. Figure 7. Two different ways of conceiving the same space, an example of how societies build and signify their landscapes.

un contexto entográfico a uno arqueológico. El autor realiza una clasificación tripartita de acuerdo al grado de vinculación de los bienes con respecto a un camino, a saber: (1) elementos sustantivos: aquellos cuya existencia solo se puede entender en relación con una vía de tránsito; (2) elementos adjetivos: aunque pudieran tener lugar al margen de la red vial, su existencia nos ayuda a entender el camino (lo adjetiva) y viceversa; (3) elementos complementarios: su existencia puede tener lugar perfectamente al margen de la existencia de una vía de comunicación, pero pueden ser de utilidad por los valores que pudieran aportar.

Este planteamiento, llevado al mundo andino y particularmente al análisis de los caminos incas, podría resultar de la siguiente manera (tabla 1):

La propuesta metodológica de ordenar en tres grupos de elementos que se debería considerar para el estudio de la vialidad inca no se contrapone a las proposiciones existentes, como por ejemplo los abordajes micro y macromorfológicos propuestos por Trombold (1991) y empleado por autores andinos como Berenguer et al. 2005 y otros. El estudio micromorfológico es particularista y se centra en las características inhe- rentes a la materialidad de la vía en sí, mientras que el macromofológico es holístico y realiza un análisis de amplio espectro geográfico distribucional de las vías y su articulación regional. En nuestra propuesta, ambos estudios formarían parte de los Elementos Sustantivos, así como las de otros autores (aunque con algunas excepciones) que sí consideran el paisaje (Raffino 1981, 2007; Pereira 1982; Niemeyer \& Rivera 1983; Santoro 1983; Hyslop 1984, 1992; Muñoz et al. 1987; Stehberg 1995; Vitry 2000; Fresco 2004; Castro et al. 2004; Berenguer et al. 2005; González 2007; Avilés 2008; Manzo et al. 2011; Moralejo 2011; Sánchez Canedo 2012; entre otros).

\section{Indicadores arqueológicos relacionados con el espacio}

A falta de "textos", los andinos recurrieron a estrategias basadas en otra lógica comunicacional, mecanismos mnemotécnicos y sistemas de registros que llegaron a tener un alto grado de sofisticación; tal es el caso de los quipus, en los que, además de datos cuantitativos relacionados con la contabilidad, aparentemente también se guardaba información espacial, pues los hilos 
Tabla 1. Tabla comparativa que sintetiza la clasificación tripartita de acuerdo al grado de vinculación de los bienes con respecto a un camino. Table 1. Comparison table that synthesizes the tripartite classification per degree of connection between goods and road.

\begin{tabular}{|c|c|c|}
\hline Elementos sustantivos & Elementos adjetivos & Elementos complementarios \\
\hline $\begin{array}{l}\text { Formados principalmente por } \\
\text { elementos artificiales, edificios } \\
\text { que componen la infraestructura } \\
\text { asociada a los caminos incas. }\end{array}$ & $\begin{array}{l}\text { Formados en su mayor parte por } \\
\text { componentes naturales que poseen } \\
\text { connotaciones simbólicas o míticas, } \\
\text { aunque hay algunos elementos } \\
\text { artificiales que lo integran. }\end{array}$ & $\begin{array}{l}\text { Todos los elementos que de una } \\
\text { u otra manera nos remiten o nos } \\
\text { ayudan a pensar en los caminos y } \\
\text { su entorno. }\end{array}$ \\
\hline $\begin{array}{l}\text { Camino y sus características in- } \\
\text { trínsecas, tambo, corpawasi, chas- } \\
\text { quiwasi, estructuras ortogonales, } \\
\text { collcas, centros administrativos } \\
\text { (kallanca, haucaypata, ushnu, etc.), } \\
\text { puestos de observación, puestos de } \\
\text { control, apachetas, mojones, mo- } \\
\text { chaderos (u otras wakas asociadas } \\
\text { al camino). }\end{array}$ & $\begin{array}{l}\text { Geosímbolos, montañas (apus, acha- } \\
\text { chilas), vertientes, lagunas, cuevas, } \\
\text { geoformas singulares y significadas } \\
\text { socialmente, Rumituru, Sayhuas, } \\
\text { Gnomon, columnas astronómicas. }\end{array}$ & $\begin{array}{l}\text { Toponimia, antroponimia, narrativa } \\
\text { del paisaje, mitos, leyendas, tradi- } \\
\text { ción oral, fiestas, cantos, idioma, } \\
\text { mapas mentales, textiles, tocapus, } \\
\text { motivos rupestres, alfarería y otros. }\end{array}$ \\
\hline
\end{tabular}

podrían haber representado los ceques y los nudos las wakas (Sánchez Canedo 2008). Asimismo, desde la antigüedad hasta el presente muchos textiles pueden ser leídos como mapas (Platt et al. 2006). También, según los cronistas, se guardaba el recuerdo a través de cantares para alabar las hazañas y proezas ancestrales, reteniendo de esta manera una memoria colectiva y generando una cartografía oral (Sanhueza 2012). Por último, existieron pinturas o tablas en las que se representaban momentos históricos y que eran conservadas en un lugar denominado Poquen Cancha, aunque lamentablemente el registro arqueológico no pudo dar con estas tablas (Rostworowski 1988).

Los caminos incas fueron concebidos con una infraestructura asociada, que fue planificada, estructurada, administrada y significada en función de cada espacio geográfico y el rol social, económico, religioso y político que cumplían dentro del Tawantinsuyu. Por otra parte, cuando hablamos de infraestructura asociada estamos haciendo referencia, entre otros, a tambos, centros administrativos de diferentes dimensiones y hasta Wamanis o capitales provinciales, las cuales no fueron emplazadas al azar, sino en espacios que tuvieron ancestralmente un valor para los pobladores del lugar o bien en nuevos espacios estratégicamente ubicados y planificados en función del entorno. Los paisajes incas tenían un carácter holístico, ya que incluían "tanto a la tierra, como al cielo, éste último refiriendo al día y a la noche, los movimientos del Sol, la Luna, las estrellas y constelaciones, formando parte importante de los calendarios agrícolas y rituales, en particular los puntos extremos de sus salidas y puestas en el horizonte" (Farrington 2015: 43).

Dentro de los elementos arquitectónicos que los incas emplearon tanto en el Cusco como en todo el Tawantinsuyu, hay algunos que poseen una particular importancia a la hora de analizar su relación con la geografía cultural y el proceso de construcción de paisajes, me refiero puntualmente a los ushnus que estaban emplazados en las aukaipata. En los ushnus no solamente se realizaban los principales rituales estatales, sino que también desde ellos se proyectaban líneas visuales sobre el horizonte montañoso que servían para organizar ritual y geográficamente el espacio. Es conocida en la literatura desde hace muchas décadas la proyección de 41 ceques que irradiaban desde el ushnu del Cusco; a nivel regional se están observando situaciones similares, como el caso del sitio El Shincal en la provincia de Catamarca, cuyas proyecciones se relacionan con una geografía sagrada y con ciclos solares y lunares (Farrington 2015: 44). Moyano (2010; Moyano \& Díaz 2015) ha investigado alineamientos astronómicos en el sitio minero Viña del Cerro en Chile, como también en el ushnu de Potrero de Payogasta y el sitio arqueológico La Ciudacita en el 
cordón del Aconquija, ubicados en el Noroeste Argentino, y sus trabajos siguen arrojando valiosa información al respecto. Por otra parte, recientes estudios realizados en el sector norte del valle Calchaquí también vinculan el arte rupestre con las montañas sagradas (Leibowicz et al. 2015), y en Potosí con fenómenos atmosféricos como son los rayos y su indisociable relación con la deidad panandina Illapa (Cruz 2015).

Numerosos autores coinciden en que uno de los principales motivos de la expansión inca en el Noroeste Argentino y el norte de Chile fue la minería. Aquellas montañas que poseían minerales tenían un plus de significación porque eran dadoras de los metales preciosos y divinizados que utilizaban los incas para sus ceremonias. Por ello, los incas llegaron a conformar paisajes mineros metalúrgicos de carácter sagrado, wakas minerales que también sirvieron para estructurar y jerarquizar el espacio (Cruz 2009; Salazar et al. 2013), las que, huelga decir, se relacionaban con los sistemas viales. Los ejemplos de materialidades vinculadas al paisaje abundan, y analizarlos excede los objetivos del presente trabajo. En forma genérica, se puede ver que, desde un punto de vista cultural y simbólico, determinados edificios y geosímbolos se encuentran amarrados al paisaje y viceversa.

\section{PALABRAS FINALES}

En los Andes no podemos comprender las sociedades sin su espacio, como tampoco podemos concebir los caminos sin la infraestructura asociada; en tal sentido, los geosímbolos y el Qhapaq Ñan se encuentran inextrincablemente unidos, la infraestructura edilicia y la simbólica no pueden estar separadas. Los geosímbolos y el paisaje adjetivan a los caminos a través de una narrativa o una cartografía oral que les da sentido de pertenencia y tradición, vinculando a las sociedades con sus ancestros que habitan en las montañas y otros lugares naturales, como describieron los cronistas y sintetizaron algunos autores (Besom 2009; Leibowicz et al. 2014).

Convencido de que la siguiente propuesta es solo la punta del ovillo, pienso que es una línea de investigación que promete mucho y, por ello, no quería dejar de plantearla en el presente artículo, que pretendió aproximarse a un análisis de relación entre los geosímbolos y el Qhapaq Ñan.
RECONOCIMIENTOS Agradezco los valiosos aportes realizados por los evaluadores del presente artículo, lo cual obligó a reorganizarlo y ciertamente mejorarlo. A Federico Viveros, encargado del área Geomática del Programa Qhapaq Nan Salta por la confección de los mapas y a Jorgelina Flores Barrantes por su apoyo incondicional.

\section{NOTAS}

${ }^{1}$ Este tipo de crecimiento es lineal y en varios sentidos o brazos, siempre siguiendo las vías de comunicación en un proceso de dispersión-concentración. En nuestro caso, tenemos los caminos incas y su infraestructura asociada, la que se manifiesta de manera regular cada cierta distancia, ya sea que se trate de tambos (20-25 $\mathrm{km})$, chasquiwasis $(6-8-\mathrm{km})$ o puestos de control, centros administrativos, etc. Lo cierto es que la ocupación del espacio se manifiesta por lo general en torno a los caminos principales, ya sea que se trate de centros urbanos o campos agrícolas o ganaderos.

${ }^{2}$ El crecimiento capilar es complementario o una consecuencia del tentacular cuando se va incrementando la población o el uso del espacio en torno a los caminos principales y sus nodos. En tal sentido, Pozo Urquizo (2011: 117) expresa que: "El tipo de crecimiento urbano capilar debe su nombre a su forma y dinámica de desplegarse sobre la difícil topografía local. Aunque nacen por su cercanía a vías principales de acceso a las ciudades al igual que las formas tentaculares, este tipo de crecimiento es diferente. Nacen de vías secundarias, caminos o senderos que parten interceptando las vías de acceso a los centros urbanos, para después adentrarse a través la topografía rural compleja y agreste. La configuración de su trama vial es como de capilares que brotan de sí mismos constantemente".

\section{REFERENCIAS}

Assmann, J., 2008. Religión y memoria cultural. Diez estudios. Buenos Aires: Lilmod.

Augé, M., 1995. Los 'no lugares'. Espacios del anonimato. Barcelona: Gedisa.

Avilés, S., 2008. Qhapaqñan. Caminos sagrados de los Inkas. La Paz: UMSA.

BASTIEN, J., 1978. La montaña del cóndor. Metáfora y ritual en un ayllu andino. La Paz: Hisbol.

BAUER, B., 2000. El Espacio sagrado de los Inkas. El sistema de ceques del Cuzco. Cuzco: Centro Bartolomé de las Casas.

BeOrChia Nigris, A., 1987. El enigma de los santuarios indígenas de alta montaña. San Juan: Centro de Investigaciones Arqueológicas de Alta Montaña (CIADAM).

Berenguer, J., 2004. Caravanas, interacción y cambio en el desierto de Atacama. Santiago: Sirawi.

Berenguer, J.; I. Cáceres, C. Sanhueza \& P. Hernández, 2005. El Qhapaqñan en el alto Loa, norte de Chile: un estudio micro y macromorfológico. Estudios Atacameños 29: 7-39. 
Bertonio, L., 1984 [1612]. Vocabulario de la lengva aymara. Cochabamba: Ceres.

BESOM, T., 2009. Of summits and sacrifice an ethnohistoric study of inka religious practices. Texas: University of Texas Press.

Betanzos, J. DE, 1987 [1551]. Suma y narración de los Incas. Madrid: Atlas.

Bonnemaison, J.,1992. Le territoire enchanté. Croyances et territorialités en Mélanésie. Géographie et cultures 3: 72-88.

Castro, V.; V. Varela, C. Aldunate \& E. Araneda., 2004. Principios orientadores y metodología para el estudio del Qhapaq Ñan en Atacama: desde el portezuelo del Inka hasta río Grande. Chungara 36 (2): 439-451.

Cieza de León, P., 2005 [1553]. Crónica del Perú. El señorío de los Incas. Caracas: Ayacucho.

Claval, P., 1999. La geografía cultural. Buenos Aires: Eudeba.

Cruz, P., 2009. Huacas olvidadas y cerros santos. Apuntes metodológicos sobre la cartografía sagrada en los Andes del sur de Bolivia. Estudios Atacameños 38: 55-74.

Cruz, P., 2015. Tatala Purita o el influjo del rayo. Arte rupestre anicónico en las altas tierras surandinas (Potosí, Bolivia). Boletín SIARB 29: 51-70.

Cruz, P. \& R. Jara, 2011. Por encima de las nubes. Caminos, santuarios y arte rupestre en la serranía de Calilegua (Jujuy, Argentina). Comechingonia 14: 75-96.

Duncan, J. S., 1990. The city as text: the politics of landscapes interpretation in the Kandyan Kingdom. Cambridge: Cambridge University Press.

Eliade, M., 1965. Paradise and utopia: mythical geography and eschatology. Daedalus: 260-280.

ELIADE, M., 1994. Lo sagrado y lo profano. Barcelona: Labor.

Farrington, I., 1998. The concept of Cusco. En Tawantinsuyu 5: 53-59.

FARrington, I., 2015. El paisaje ritual en el Shincal de Quimivil. La importancia de los estudios arqueoastronómicos. En El Shincal de Quimivil. Una capital inka al sur del Kollasuyo, Raffino, R.; L. Iácona, R. Moralejo, D. Gobbo \& M. Couso, Eds., pp. 41-63. Buenos Aires: Fundación de Historia Natural Félix Azara.

Foucault, M., 2008. Topologías. Fractal (48): 39-62. <http:// www.mxfractal.org/RevistaFractal48MichelFoucault.html> [Consultado 20-12-2016].

Fresco, A., 2004. Ingañan. La red vial del imperio inca en los andes ecuatoriales. Quito: Banco Central del Ecuador.

González, C., 2007. Qhapaq Ñan en el extremo meridional del despoblado de Atacama, Chile. Actas del XVI Congreso Nacional de Arqueología Argentina, tomo II, pp. 511-518. San Salvador de Jujuy: Universidad Nacional de Jujuy.

González Holguín, D., 1989 [1608]. Vocabulario de la lengua general de todo el Perú llamada lengua quechua o del Inka. Lima: Universidad Nacional Mayor de San Marcos.

Greimas, A. J., 1980. Semiótica y ciencias sociales. Madrid: Fragua. Hyslop, J., 1984. The Inka road system. Orlando: Academic Press.

HYslop, J., 1992. Qhapaqñan, el sistema vial inkaico. Lima: Instituto de Estudios Andinos.
Leibowicz, I.; C. Jacob, F. Acuto \& A. Ferrari, 2014. Paisajes rituales incaicos. Una mirada desde las crónicas coloniales. Haucaypata Investigaciones arqueológicas del Tahuantinsuyo 3 (8): 123-131.

Leibowicz, I.; A. Ferrari, C. Jacob \& F. Acuto, 2015. Petroglifos en el valle Calchaquí Norte (Salta, Argentina): camélidos, montañas y apropiación inkaica del paisaje local. Chungara (4): $575-587$

Manzo, A., P. Delcourt \& D. Gutiérez, 2011. La red vial prehispánica en el sur de Bolivia. Una visión del espacio $y$ construcción social del paisaje en los caminos Inkas. La Plata: Yáhuar.

Moralejo, R., 2011. Los Inkas al sur del valle de Hualfín: organización del espacio desde una perspectiva paisajística. Tesis para optar al título de Doctor en Ciencias Naturales. Facultad de Ciencias Naturales y Museo, Universidad Nacional de La Plata, La Plata. <http://sedici.unlp.edu.ar/handle/10915/5242> [Consultado 23-01-2017].

Moyano, R., 2010. El ushnu y la astronomía de horizonte en Viña del Cerro. Chungara 42 (2): 419-432.

Moyano, R. \& M. Díaz, 2015. Los nevados del Aconquija, como sitio de frontera y espacio de observación lunar, Tucumán, noroeste de Argentina. Estudios Atacameños 50: 151-175.

Muñoz, I.; J. Chacama \& G. Espinosa, 1987. El poblamiento prehispánico tardío en el valle de Codpa: una aproximación a la historia regional. Chungara 19: 7-61.

Murra, J., 2002. El mundo andino. Población, medio ambiente y economía. Lima: IEP-PUCP.

Nielsen, A., 1997. El tráfico caravanero visto desde La Jara. Estudios Atacameños 14: 339-371.

Nielsen, A. \& W. WALker, 1999. Conquista ritual y dominación política en el Tawantinsuyu. El caso de los Amarillos (Jujuy, Argentina). En Sed non satiata. Teoría social en la arqueología latinoamericana contemporánea, Zarankin, A. \& F. Acuto, Eds., pp. 153-169. Buenos Aires: Ediciones del Tridente.

Nielsen, A. \& L. Boschi, 2007. Celebrando con los antepasados. Arqueología del espacio público en Los Amarillos. Quebrada de Humahuaca, Jujuy, Argentina. Argentina: Mallku.

Niemeyer, H. \& M. RiverA, 1983. Un Camino Inca en el despoblado de Atacama. Boletín de Prehistoria de Chile 9: 91-193.

NiLEs, S., 1992. La arquitectura incaica y el paisaje sagrado. En The ancient Americas: art from sacred landscapes, R. Townsend, Ed., pp. 347-357. Chicago: Art Institut of Chicago.

NúÑEZ, L. \& T. Dillehay, 1995 [1979]. Movilidad giratoria, armonía social y desarrollo en los Andes meridionales: patrones de tráfico e interacción económica. Antofagasta: Universidad Católica del Norte.

Otero Vilariño, C., 2003. Una ruta cultural en Ortegal: o camiño dos arrieiros. TAPA. Traballos de Arqueoloxía e Patrimonio 30. Santiago de Compostela: Universidade de Santiago de Compostela. <http://digital.csic.es/bitstream/10261/6167/1/ TAPA30.pdf $>$ [Consultado 23-01-2017].

Pereira, D., 1982. La red vial incaica en Cochabamba. Cuadernos de investigación. Serie Arqueología 1: 55-88. 
Platt, T., T. Bouysse-Cassagne \& O. Harris, 2006. QaraqaraCharca. Mallku, Inka y rey en la provincia de Charcas (siglos $\mathrm{XV}$-XVII). Historia antropológica de una confederación aymara. La Paz: IfEA-Plural-University of St. Andrews-University of London-InterAmerican Foundation-Fundación Cultural del Banco Central de Bolivia.

Guamán Poma de Ayala, F. 1992 [1614]. Nueva crónica y buen gobierno. México DF: Siglo XXI.

Pozo Urquizo, R., 2011. Nuevos tipos de crecimiento urbano en ciudades pequeñas localizadas. Reestructuración geográfica del territorio por la salmonicultura y sus consecuencias espaciales en cinco ciudades de Chiloé, 1982-2008. Tesis para optar al título de Magíster en Desarrollo Urbano. Instituto de Estudios Urbanos y Territoriales, Pontificia Universidad Católica de Chile. <http://repositorio.educacionsuperior. gob.ec/bitstream/28000/1226/1/T-SENESCYT-000357.pdf> [Consultado 23-01-2017].

Raffino, R., 1981. Los Inkas del Kollasuyu. La Plata: Ramos Americana.

Raffino, R., 2007. Poblaciones indigenas en Argentina. Urbanismo y proceso social precolombino. Buenos Aires: Emecé.

Reinhard, J. \& C. Ceruti, 2000. Investigaciones arqueológicas en el volcán Llullaillaco: complejo ceremonial incaico de alta montaña. Salta: Universidad Católica de Salta.

Rostworowski de Diez Canseco, M., 1988. Historia del Tawantinsuyu. Lima: IEP.

Salazar, D.; J. Berenguer \& G. Vega. 2013. Paisajes minerometalúrgicos incaicos en Atacama y el altiplano sur de Tarapacá (norte de Chile). Chungara 45 (1): 83-103.

SÁnchez CAnedo, W., 2008. Inkas, "flecheros" y mitmaqkuna. Cambio social y paisajes culturales en los valles y en los yungas de Inkachaca/Paracti y Tablas Monte (Cochabamba-Bolivia, siglos $\mathrm{XV}$-XVI). Uppsala: Instituto de Investigaciones Arqueológicas. <http://www.diva-portal.org/smash/get/diva2:172393/ FULLTEXT01.pdf> [Consultado 23-01-2017].

SÁnchez CANedo, W., 2012. Cruzando paisajes, transitando caminos: el ramal inca de Sipe Sipe hasta Inkachaca (Cochabamba, Bolivia). En The past ahead. Language, culture, and identity in the neotropics, Ch. Isendahl, Ed., pp. 207-227. Västerås: Uppsala University.

SÁnCheZ, J. E., 1992. Geografía política. Madrid: Síntesis.

SAnhueza, C., 2004. Medir, amojonar, repartir: territorialidades y prácticas demarcatorias en el camino incaico de Atacama (II Región, Chile). Chungara 36 (2): 483-494.

SAnhueza, C., 2012. Las 'sayhuas' del Inca. Territorio, frontera, geografía sagrada y 'cartografía' oral en el desierto de Atacama. Tesis para optar al grado de Doctora en Historia con Mención en Estudios Andinos, Escuela de Posgrado, Pontificia Universidad Católica del Perú. Lima.

SAntoro, C., 1983. Camino del Inca en la sierra de Arica. Chungara 10: 47-55.

Schobinger, J. 1998. Arqueología de alta montaña: santuarios incaicos en los Andes centro-meridionales. Beiträge zur Allgemeinen und Vergleichenden Archäologie (18): 363-399. Mainz: Philipp von Zabern.
Stehberg, R., 1995. Instalaciones incaicas en el norte y centro semiárido de Chile. Santiago: Dibam.

Trombold, C., 1991. An introduction to the study of ancient New World road networks. En Ancient road networks and seattlements hierachies in the New World, C. Trombold, Ed., pp. 1-9. Cambridge: Cambridge University Press.

VITRY, C., 1997. Arqueología de alta montaña. Argentina. Yachayruna Revista de Divulgación científica (1): 16-23.

VITry, C., 2000. Aportes para el estudio de caminos incaicos. Tramo Morohuasi-Incahuasi. Salta-Argentina. Salta: Gofica.

Vitry, C., 2005. Ocupación inka en la quebrada del Toro. Salta, Argentina. Xama (15-18): 5-19.

Vitry, C., 2010 Ms. Reverso del espacio geográfico andino. Una propuesta desde la arqueología del paisaje. Ponencia presentada en el Coloquio Internacional Avesso. Percepção artístico-urbana e dimansão socio-espacial. Río de Janeiro 23 y 24 de junio de 2010. 